\title{
Micro-Mechanisms and Modeling of Ductile Fracture Initiation in Structural Steel after Exposure to Elevated Temperatures
}

\author{
Yazhi Zhu ${ }^{1,2} \oplus$, Shiping Huang ${ }^{3,4, *}$ and Hizb Ullah Sajid ${ }^{5} \mathbb{C}$ \\ 1 Key Laboratory of Performance Evolution and Control for Engineering Structures of Ministry of Education, \\ Tongji University, Shanghai 200092, China; yzzhu@tongji.edu.cn \\ 2 Department of Structural Engineering, Tongji University, Shanghai 200092, China \\ 3 School of Civil Engineering and Transportation, South China University of Technology, \\ Guangzhou 510640, China \\ 4 China-Singapore International Joint Research Institute, Guangzhou 510700, China \\ 5 Department of Civil and Environmental Engineering, North Dakota State University, Fargo, ND 58105, USA; \\ hizbullah.sajid@ndsu.edu \\ * Correspondence: ctasihuang@scut.edu.cn
}

Citation: Zhu, Y.; Huang, S.; Sajid, H.U. Micro-Mechanisms and Modeling of Ductile Fracture Initiation in Structural Steel after Exposure to Elevated Temperatures. Metals 2021, 11, 767. https://doi.org/ 10.3390/met11050767

Academic Editors: Giovanni Meneghetti and Andrey Belyakov

Received: 2 April 2021

Accepted: 5 May 2021

Published: 7 May 2021

Publisher's Note: MDPI stays neutral with regard to jurisdictional claims in published maps and institutional affiliations.

Copyright: () 2021 by the authors. Licensee MDPI, Basel, Switzerland. This article is an open access article distributed under the terms and conditions of the Creative Commons Attribution (CC BY) license (https:// creativecommons.org/licenses/by/ $4.0 /)$.

\begin{abstract}
This paper aims to (1) study ductile fracture behavior, and (2) provide a computational tool for predicting fracture initiation in ASTM A572 Gr. 50 structural steels under axisymmetric tension loading are heated to elevated temperatures and cooled down in air and in water. Employing the post-fire test results reported in the literature for A572 Gr. 50 steels, this paper carries out coupon-level finite element (FE) simulations to capture the stress and strain fields and explore the micro-mechanism of post-fire fracture in ASTM A572 Gr. 50 steels, respectively. Numerical results show that the effects of the experienced temperature and cooling method on fracture parameters are more significant for the steels cooled after being heated to temperatures from $800{ }^{\circ} \mathrm{C}$ to $1000{ }^{\circ} \mathrm{C}$ than those from $500{ }^{\circ} \mathrm{C}$ to $700{ }^{\circ} \mathrm{C}$, due to microstructural changes during the cooling process. Aircooled and water-cooled specimens show an improvement and a significant reduction in ductility, respectively. A modified void growth model (VGM) is proposed by introducing two additional temperature-dependent functions, through which the effects of elevated temperature and cooling method on fracture behavior are quantitatively analyzed. Limitations of this study are also discussed.
\end{abstract}

Keywords: post-fire behavior; ductile fracture; stress triaxiality; elevated temperature; cooling method

\section{Introduction}

Structural fire accidents commonly result in the loss of life and property [1,2]. Structural fire safety has thus gained increasing attention in the structural engineering community $[3,4]$. Steel structures experience excessive deformations and deterioration in mechanical behavior during and after a fire accident, partly due to the significant degradation of mechanical properties of structural steels after exposure to high temperatures [5]. Previous fire accidents have shown that numerous steel structures, though undergoing severe local damage, avoided complete collapse due to sufficient structural redundancy, as well as assistance from passive and active fire protection systems [6]. The focus has thus shifted to resilience of steel structures after fire hazards. Evaluation of post-fire behavior of steel structures is of great importance for subsequent decision-making and planning for structural strengthening and retrofitting, as well as for improving the fire-resistant design of new steel structures [7-9]. A reliable and accurate assessment of post-fire mechanical performance at the structural level is strongly dependent on the understanding of post-fire mechanical properties of steels at the material level, which provides fundamentals for the evaluation procedure for the post-fire reusability of steel structures.

Since the collapse of World Trade Center Buildings, significant research efforts have been devoted to investigating the post-fire mechanical properties of structural steels 
used in the United States and numerous other countries, covering a wide range of steel grades [10-36]. The general objective of these studies is to examine the residual modulus of elasticity, yield and ultimate tensile strengths, and the ductility of structural steels after being heated to various temperatures and cooled down using different methods [1,21,27]. Among the mechanical properties, post-fire ductility, a measure of material elongation to fracture, is a crucial parameter for evaluating the ultimate behavior of post-fire steel structures. Stress triaxiality (ratio of hydrostatic stress to von Mises equivalent stress, $\eta$ ) is a well-recognized key parameter affecting the fracture initiation process, as well as the ductility of steels at room temperature [37-39]. Previous preliminary studies suggested that stress triaxiality may also be of great importance to the fracture initiation of post-fire steels, thus post-fire ultimate deformation capacity of steel members and structures $[1,12,15]$. It is essential to understand the role of stress triaxiality on the physical mechanisms of fracture in post-fire steels. However, standard uniaxial tension tests on post-fire steels using unnotched dog-bone specimens do not exhibit various levels of stress triaxiality, thus are inadequate for a fundamental understanding and accurate modeling of ductility and fracture in post-fire steels [38,39]. Motivated by these, extended studies are urgent on stress triaxiality-dependent fracture behavior of post-fire steels, serving to advance the understanding of the ultimate capacity of steel structures after fire events.

Fracture initiation in structural steels at room temperature is dominated by ductile modes, which have gained great interest during the last two decades [38-42]. While the fracture behavior of room temperature structural steels is well established, limited studies are reported on the post-fire fracture behavior of structural steels $[1,12,27]$. Sajid and Kiran [12] observed similar fractography in ASTM A36 steels after the experienced heating and cooling process compared to specimens at room temperature using a scanning electron microscope. The important roles of stress triaxiality, elevated temperature exposure, and cooling method on fracture behavior of structural steels has been previously highlighted $[1,12,15]$, but not adequately addressed in the literature. To bridge the gap between the understanding of the underlying physics of post-fire fracture initiation in structural steels and the structural performance assessment, this paper focuses on the development of a post-fire fracture model based on the micro-mechanical analyses of post-fire fracture in structural steels. The present study aims to gain insights into the fracture mechanism in ASTM A572 Gr. 50 structural steels after being heated to high temperatures, and investigate the sensitivity of fracture initiation to elevated temperature, cooling method. As the dominated role of stress triaxiality during ductile fracture process is clear for steels under axisymmetric tension loading conditions [38-42], this study focuses on the fracture behavior under the specific loading case. Another important objective is to provide an effective computational tool for predicting post-fire fracture initiation in ASTM A572 Gr. 50 steels.

This paper begins with reviewing the experimental program and test results of the post-fire mechanical properties of ASTM A572 Gr. 50 structural steels, as reported in a previous study [1]. Finite element modeling is subsequently performed to identify the continuum stress and strain fields in each specimen, corresponding to different temperatures and triaxiality values. Moreover, the micro-mechanism of fracture initiation in A572 Gr. 50 structural steels after heating and cooling down is investigated through experimental evidence. The commonly used micromechanics-based void growth model (VGM) is introduced to predict post-fire ductile fracture in A572 Gr. 50 steels and is calibrated using experimental and numerical results. Finally, a modified VGM model for post-fire ductile fracture initiation in A572 Gr. 50 steels is proposed, incorporating the effects of temperature, and the cooling method. The key elements of the proposed model include two residual factors for ductile fracture properties. Limitations of the proposed model are also discussed. 


\section{Review of Experimental Study}

Sajid and Kiran [1] experimentally evaluated the post-fire mechanical properties of ASTM A572 Gr. 50 steels, along with their dependency on stress triaxiality, elevated temperature, and cooling method. To acquire axisymmetric loading condition and various stress triaxialities in the specimens, both smooth round (SPR) and notched specimens were prepared. For the notched specimens, four circular notches with different radii (CN1, $\mathrm{CN} 2, \mathrm{CN} 3$, and UN1) and two types of $\mathrm{V}$ notches (VN1 and VN2) were incorporated into the test specimens (Figure 1). The specimens were first heated to a range of targeted temperatures including $500{ }^{\circ} \mathrm{C}, 600{ }^{\circ} \mathrm{C}, 700{ }^{\circ} \mathrm{C}, 800{ }^{\circ} \mathrm{C}, 900{ }^{\circ} \mathrm{C}$, and $1000{ }^{\circ} \mathrm{C}$, at a rate of $10 \pm 2{ }^{\circ} \mathrm{C} / \mathrm{min}$ in an electric furnace and subjected to the target temperatures for a $1-\mathrm{h}$ period. The specimens were then cooled down to room temperature (RT, $\sim 25^{\circ} \mathrm{C}$ ) with two cooling methods, i.e., cool-in-air (AC, moving the specimens from the furnace and placing them at room temperature of $25^{\circ} \mathrm{C}$ for $1 \mathrm{~h}$ ) and cool-in-water (WC, cooling in a water bath at room temperature of $25^{\circ} \mathrm{C}$ ). Post-fire mechanical properties were then evaluated using uniaxial tension tests on both the reference room temperature specimens (RT) and post-fire specimens (AC and WC). To complement these results, this study emphasizes the post-fire ductile fracture behavior and modeling of ASTM A572 Gr. 50 steels, and for this purpose, the experimental load-displacement responses for the SPR specimens reported in Sajid and Kiran [1] are used (Figure 2). The true stress-strain curve of steel for a given temperature and cooling method is calibrated from the corresponding SPR specimen, through a nonlinear finite element analysis and by using an iterative approach described elsewhere [43].
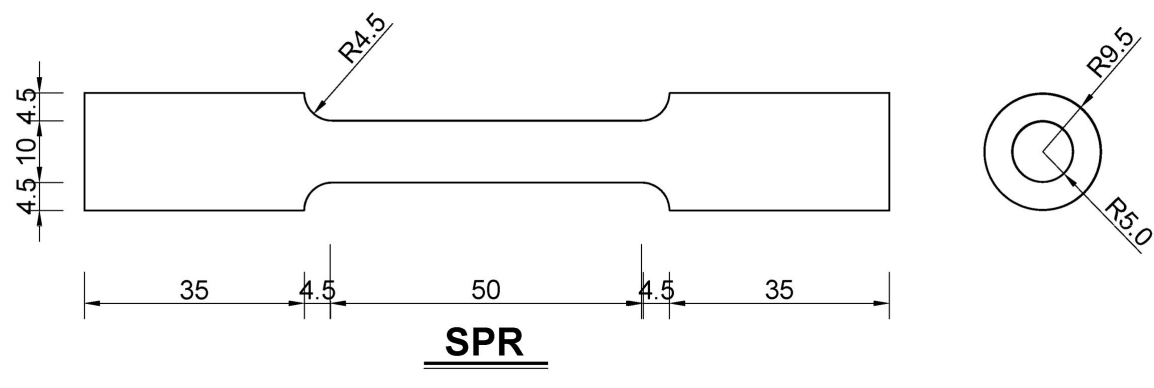

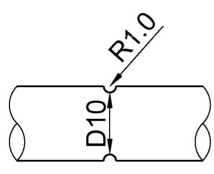

CN1

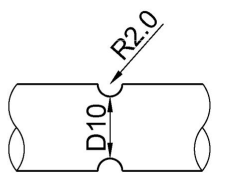

CN2

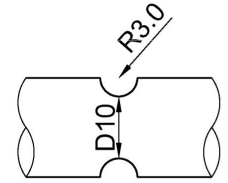

CN3

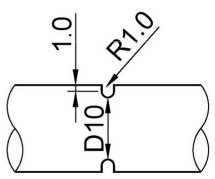

UN1

Figure 1. Geometries of the test un-notched and notched specimens (all dimensions are in $\mathrm{mm}$ ). 

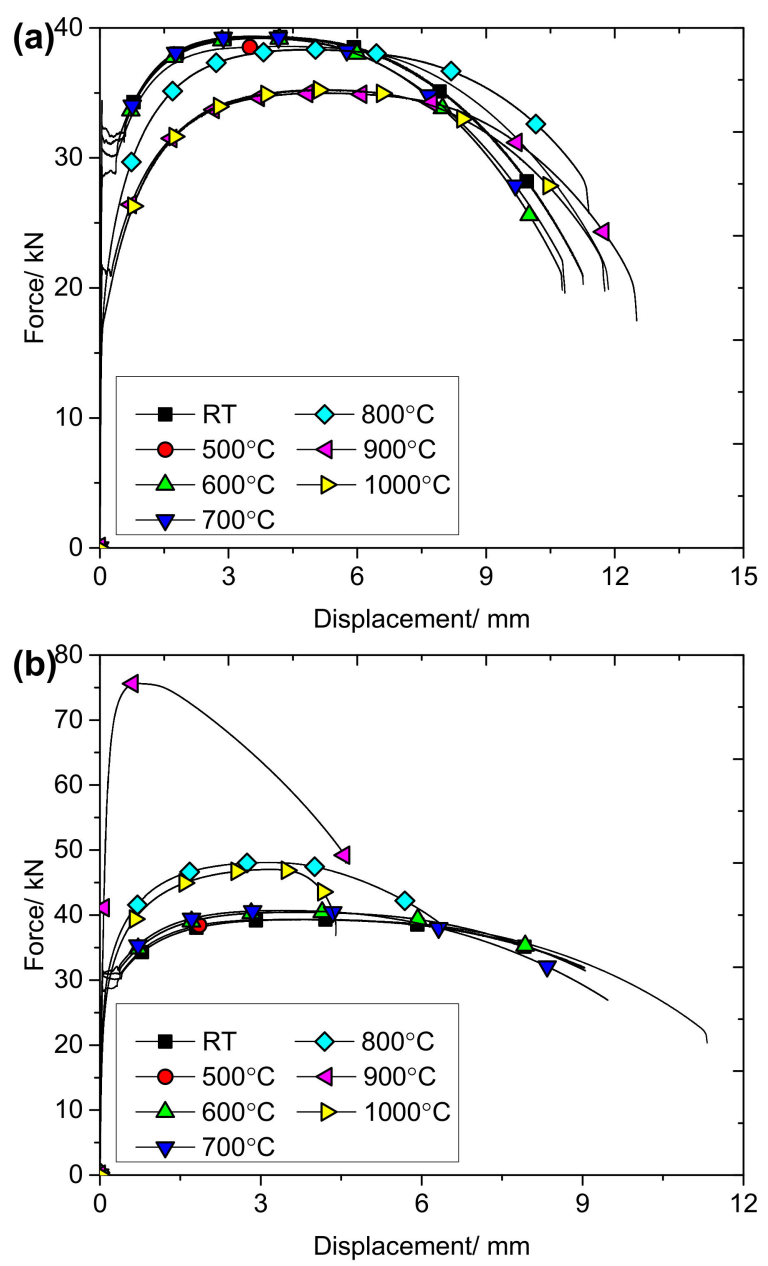

Figure 2. Load displacement curves of the SPR specimens, (a) air-cooled, and (b) water-cooled.

\section{Finite Element Modeling}

Finite element modeling of fracture specimens is carried out using the finite element (FE) program ABAQUS ${ }^{\circledR}$ (2016, Dassault Systèmes Simulia, Providence, RI, USA) [44] to analyze the continuum stress and strain fields as well as predict ductile fracture initiation. Each cylindrically notched specimen is modeled as a two-dimensional axisymmetric model employing four-noded bilinear axisymmetric full integration elements (CAX4). Exploiting the symmetry in both the $\mathrm{X}-$-, and $\mathrm{Y}$-direction, only one-fourth of the specimen is modeled in this study. A typical FE model with the corresponding boundary and loading conditions is provided in Figure 3. Using mesh sensitivity studies, the mesh sizes are refined for each FE model. Moreover, the size of the element in the critical regions of the specimen must be smaller than the characteristic length (a detailed discussion about the characteristic length is provided in Section 5.2) to accurately capture the gradients of stress and strain fields. Consequently, $0.05 \mathrm{~mm}$ and $0.5 \mathrm{~mm}$ elements are selected for the critical and noncritical regions, respectively, within the FE model. Material nonlinearity is considered to be associated with the J2 isotropic hardening model. The true stress-plastic strain relationship of the steel specimen after heating and cooling down shown in Figure 4 is evaluated using the corresponding SPR specimen (see Zhu et al. [43] for a detailed description of calibration). To further validate the calibrated true stress-strain relationships, the numerical load-displacement response for each notched specimen is compared with the experimental load-displacement curve. Figure 5 presents an example of the load-displacement responses of the $500{ }^{\circ} \mathrm{C}-\mathrm{AC}$ series of specimens. The numerical results are in good agreement with the test response until fracture (Figure 5). 


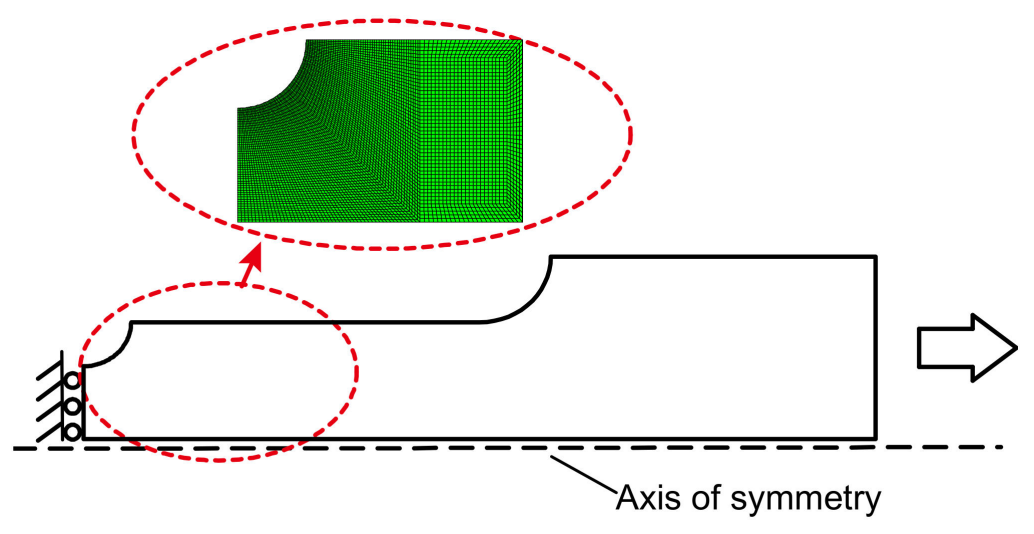

Figure 3. Illustration of the finite element model for the notched specimen.
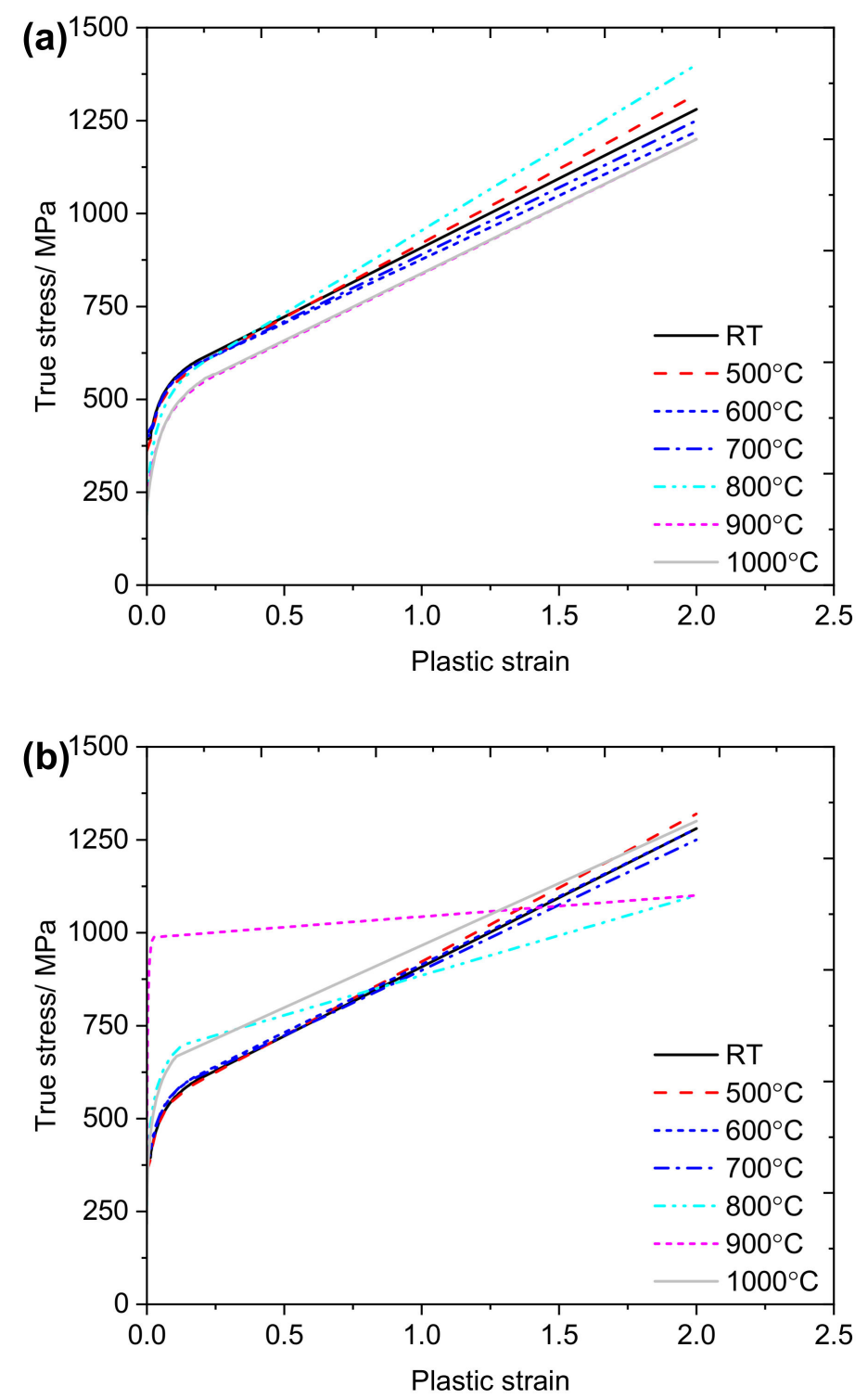

Figure 4. True stress-plastic strain relationship for ASTM A572 Gr. 50 after heating to elevated temperatures and cooling, (a) in air, and (b) in water. 


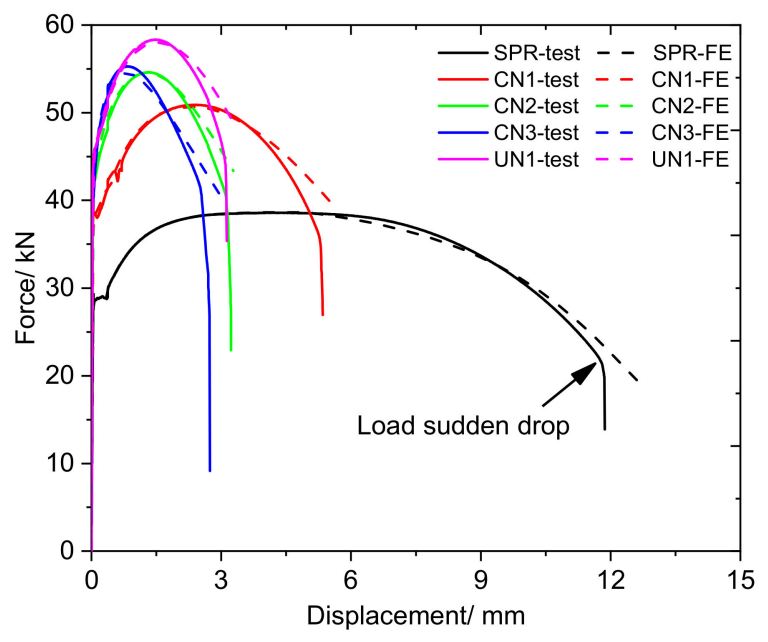

Figure 5. Experimental and numerical load-displacement response of the specimens after heating to $500{ }^{\circ} \mathrm{C}$ and cooling in air.

As mentioned previously, the stress and strain fields in each specimen, which are required for investigating the fracture behavior of the post-fire steel specimens, are obtained using FE simulations. Variation of stress triaxiality with plastic strain at the center of the RT and 500-AC and $500{ }^{\circ} \mathrm{C}-\mathrm{WC}$ specimens is shown in Figure 6. In general, the magnitude of triaxiality varies with the deforming notch shape. For specimens exposed to a given temperature and cooled down using a given method (or RT specimens), the initial stress triaxiality at the center of the specimen ranges from 0.33 to 0.82 , and the triaxiality evolved significantly during the loading history. Slight differences can be observed in the stress triaxiality among the specimens after heating and cooling down from different temperatures with the same notch geometry, which may be a result of the changing plastic flow rule caused by the microstructural changes in steels cooled from high temperatures under different cooling methods [15]. However, the effects of elevated temperature and cooling method on stress triaxiality are relatively insignificant compared to the effect of notch geometry. Variation in the plastic flow rule may influence not only stress triaxiality but also fracture initiation mechanisms [1,12].
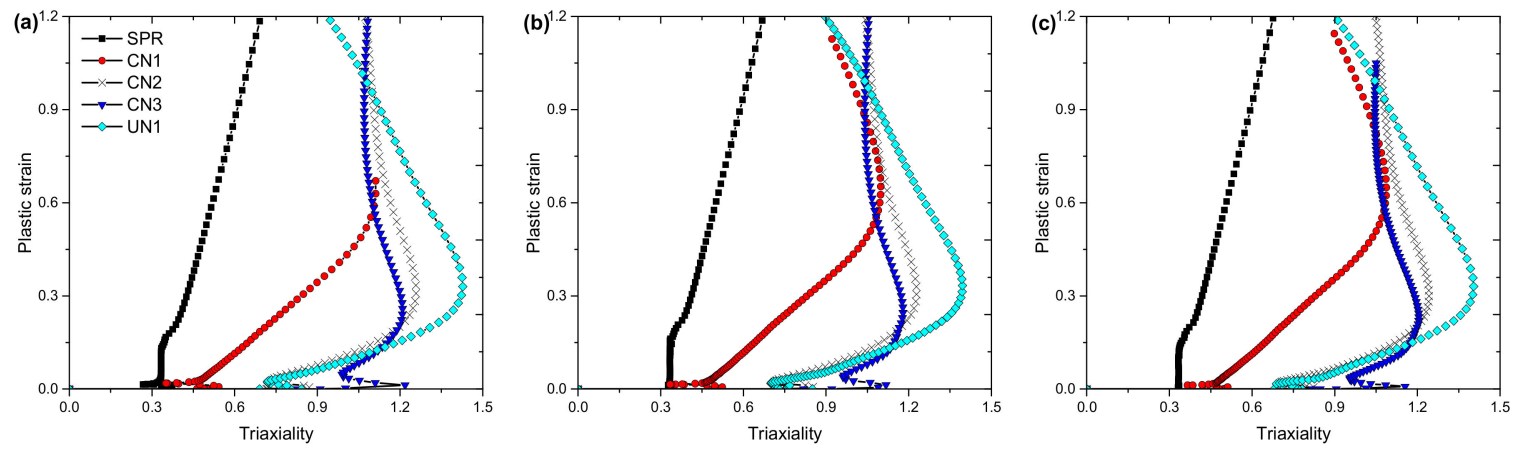

Figure 6. Stress triaxiality vs. plastic strain at the center of the cross-section for test specimens, (a) $\mathrm{RT}$, (b) $500{ }^{\circ} \mathrm{C}-\mathrm{AC}$, and (c) $500{ }^{\circ} \mathrm{C}-\mathrm{WC}$.

\section{Micro-Mechanisms of Post-Fire Fracture in A572 Steels}

The underlying micro-mechanisms leading to fracture initiation are relatively well established for structural steels like ASTM A36 [37] A572 [37], and A992 [45] steels at room temperature, as well as under the influence of high stress triaxialities. Ductile fracture initiation involves three stages, consisting of void nucleation, growth, and coalescence [38,39]. Void nucleation occurs at inclusions or at the interface between softer and harder metallurgical phases. For a given steel, further straining leads to increasing void size that is 
dependent on the macroscopic stress and strain conditions. Further void growth results in the interaction and breakage of the material matrix between neighboring voids (referred to as void coalescence), leading to crack initiation. The fracture initiation location is characterized by microscopic cups and cones or dimples, which is referred to as the micro-void coalescence (MVC) zone [12,45]. In contrast, a multifaceted river-like surface is typical of cleavage or brittle fracture [38].

To the best of the authors' knowledge, micro-mechanisms of fracture initiation have rarely been investigated in structural steels after exposed to elevated temperatures. The only documented studies on post-fire fracture behavior of structural steels are reported by Sajid and Kiran [12] for ASTM A36 steel and Kang et al. [13] for HSSS Q690 steel. Fractography from ASTM A572 steel specimens after heating and cooling down are shown in Figure 7. These fractographs are obtained using a JEOL JSM-6490LV variable-pressure scanning electron microscope system at different magnifications. For the SPR specimen made of ASTM A572 steels cooled from $1000^{\circ} \mathrm{C}$ (Figure $7 \mathrm{~b}, \mathrm{c}$ ), the MVC and river-like zones coexist at the site of fracture initiation on a given fracture surface. A similar phenomenon observed in structural steels at room temperature is fairly well recognized as ductile fracture initiation followed by brittle crack growth [38,39]. A common mechanism for extensive initiation and the growth of cleavage cracks is the formation of microcracks induced by ductile fracture that provides the stress concentration exceeding the trans-granular cleavage bond strength. Ductile microcrack growth followed by the initiation of cleavage fracture is associated with extensive plasticity. In other words, fracture initiation in structural steels at room temperature is primarily dominated by a ductile mode, and the subsequent crack growth transitions into a brittle mode $[38,39]$. Fracture initiation in ASTM A572 steels after exposure to elevated temperatures is believed to follow a similar mechanism. Evidences for this micro-mechanism includes: (1) similar fractography on the fracture surface of post-fire steels as RT specimens (containing both MVC and river-like cleavage fracture zones), shown in Figure $7 b, c$, and (2) the high ductility of each specimen after exposed to high temperatures (particularly the air-cooled specimens) as listed in Table 1, which is a manifestation of high plasticity. Sajid and Kiran [12] suggested that fracture initiation in ASTM A36 steels after cooling down from high temperatures is attributed to a ductile mode. A comparison of ductility between ASTM A36 [12] and ASTM A572 [1] steels under a given heating and cooling scenarios revealed that the specimens made of ASTM A572 steels exhibited even higher ductility than ASTM A36 specimen, implying a high plasticity in A572 Gr. 50 steel specimens that are air-cooled down from elevated temperatures. This further suggests that fracture initiation in post-fire ASTM A572 steels is also controlled by a ductile mode.

Table 1. Post-fire ductility (\%) of SPR specimens made of ASTM A36 and A572 Gr. 50 steels ${ }^{1}$.

\begin{tabular}{cccc}
\hline Temperature $\left({ }^{\circ} \mathbf{C}\right)$ & Cooling Method & ASTM A36 & ASTM A572 Gr. 50 \\
\hline RT & - & 40.31 & 45.06 \\
500 & AC & 40.86 & 47.41 \\
& WC & 40.17 & 45.29 \\
600 & AC & 44.13 & 43.10 \\
& WC & 43.99 & 43.61 \\
700 & AC & 49.22 & 43.35 \\
& WC & 34.06 & 39.90 \\
800 & AC & 38.77 & 45.57 \\
& WC & 24.92 & 25.53 \\
900 & AC & 44.85 & 50.05 \\
& WC & 15.73 & 18.33 \\
\multirow{2}{*}{1000} & AC & 44.83 & 47.07 \\
& WC & 12.60 & 14.17 \\
\hline
\end{tabular}

Note: Ductility is defined as the ratio of the measured elongation (where a sudden load dropping occurs) to the original gauge length. ${ }^{1}$ Data for ASTM A572 Gr. 50 and A36 steels were extracted from references [1,12], respectively. 

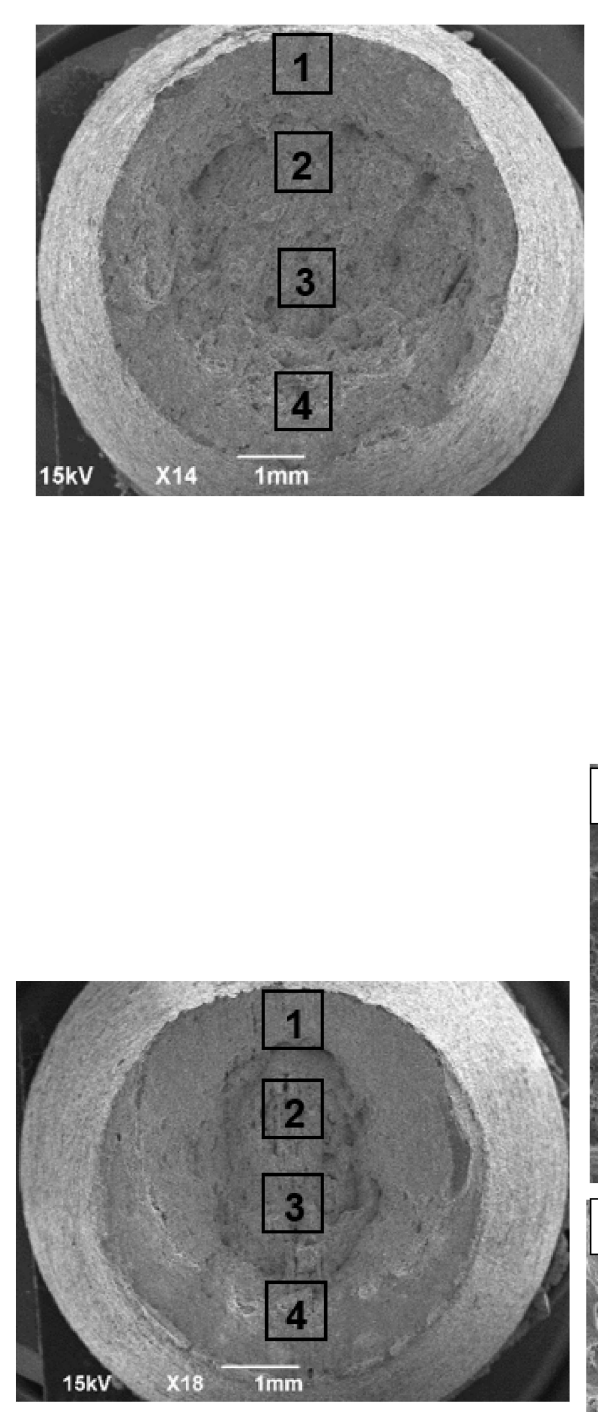
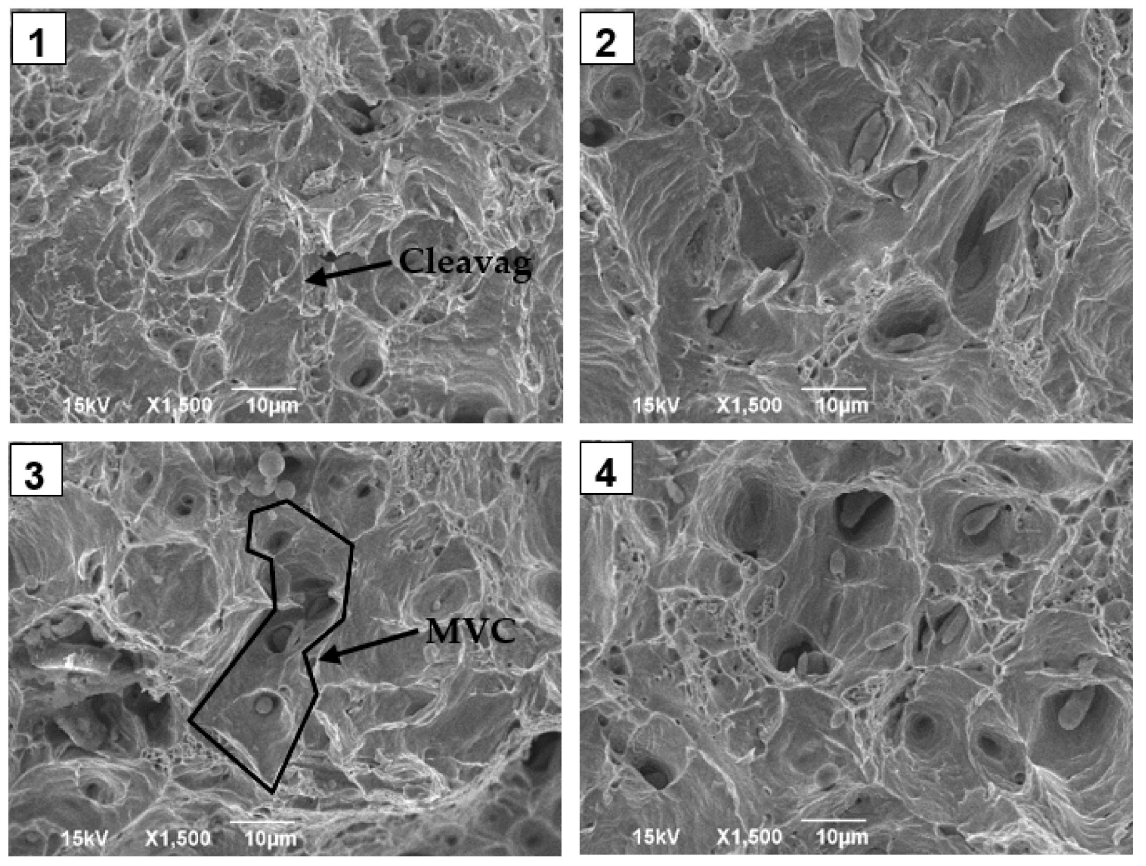

(a)
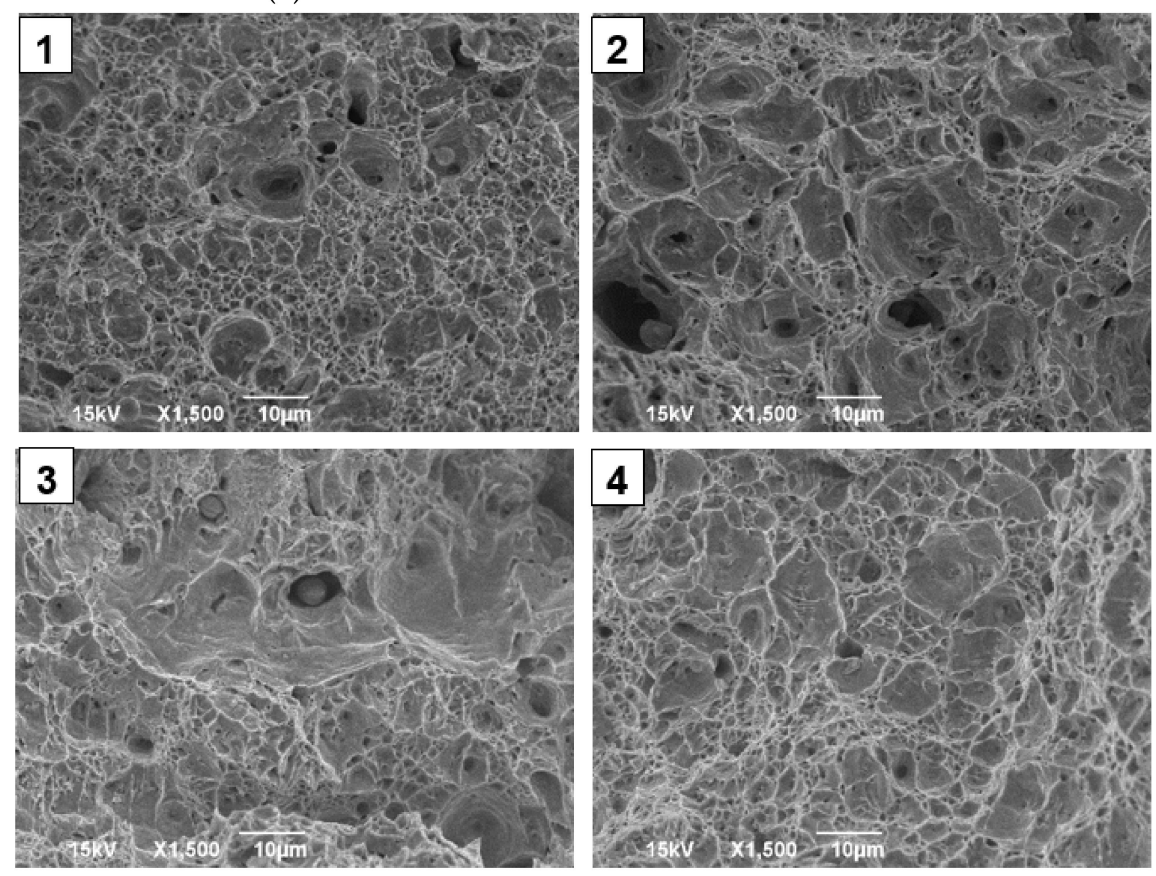

(b)

Figure 7. Cont. 

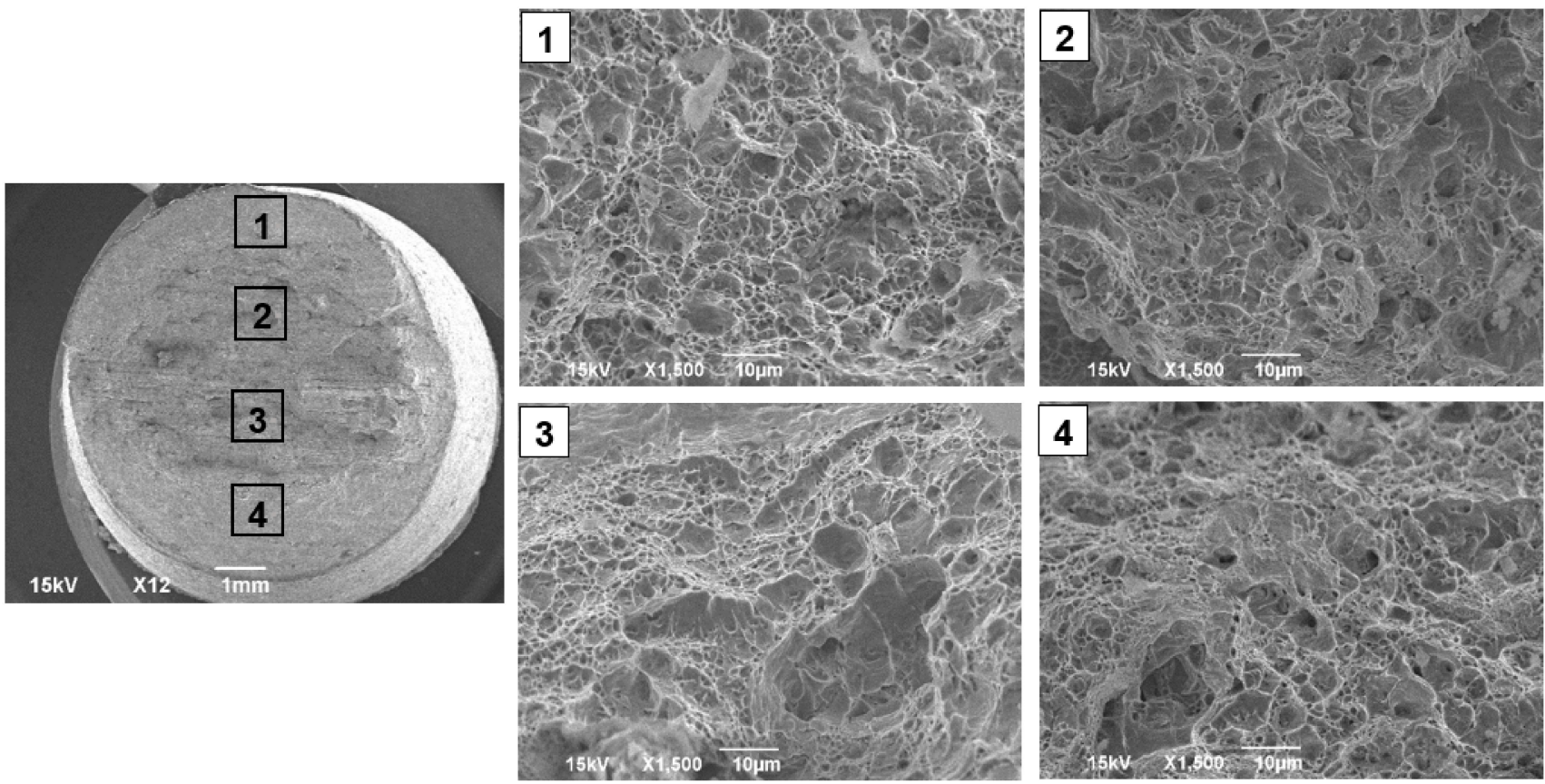

(c)

Figure 7. Scanning Electron Microscope (SEM) fractographs (JEOL, Tokyo, Japan) of ASTM A572 Gr. 50 steel, (a) SPR RT specimen, (b) SPR-1000-AC, and (c) SPR-1000-WC.

The mechanism of ductile fracture initiation is influenced by many factors, e.g., the stress and strain fields, plastic flow rule, and microstructures, which determine the complexity of the ductile fracture process [46,47]. These factors are highly relevant to stress triaxiality, temperature, and cooling method in steels cooled from elevated temperatures and reasonably affect the MVC extent. The MVC zones in the SPR-RT-specimen and SPR-1000-AC specimen are comparable, both of which are larger than that in the SPR-1000WC-specimen (Figure 7). The extent of cleavage fracture in the SPR-1000-WC-specimen, which is observed to be much larger than that in the SPR-RT and SPR-1000-AC specimens, can be used to explain the significant reduction of ductility in the SPR-1000-WC-specimen. It is suggested that the cooling process influences the extent of cleavage fracture zones, along with the steel ductility. Moreover, temperature is believed to have a significant influence on the micro-mechanisms of structural steels after being exposed to elevated temperatures $[1,10,17]$. However, SEM analyses provide limited information regarding the temperature effect, due to a lack of test data outside the temperature points (RT and $1000{ }^{\circ} \mathrm{C}$ ). To gain deeper insight into the combined effects of elevated temperature and cooling method on micro-mechanisms, detailed micromechanical analyses are required in the further studies.

\section{Micromechanics-Based Model for Post-Fire Ductile Fracture}

Experimental studies and coupon-level FE simulations provide access to coupon-level component responses, true stress-strain relationships, as well as stress and strain fields within each notch. Studies on fracture micro-mechanisms confirm that ASTM A572 steels after being cooled down from elevated temperatures exhibited a similar fracture initiation mode compared to steels at room temperature (i.e., a ductile mode). This section aims to further provide a quantitative tool for predicting post-fire ductile fracture initiation in ASTM A572 Gr. 50 structural steels.

The abovementioned micro-mechanical analyses have confirmed that post-fire fracture in ASTM A572 Gr. 50 structural steels follows the ductile mode, like that in steels without the heating and cooling treatment. It is thus reasonable to postulate that the void growth is the controlling step for ductile fracture initiation in post-fire A572 Gr. 50 steels [38]. To this 
end, the popular criteria for ductile fracture initiation in steels at room temperature may be applicable for steels cooled after exposure to elevated temperatures. As the focus of this study is on ductile fracture initiation at high triaxialities, the well-established models commonly employed for high triaxialities may be suitable to use as the basis of the model for post-fire ductile fracture. Among various models, the void growth model (VGM) developed by McClintock (1968) [48] and Rice and Tracey (1969) [42] has demonstrated success in many practical applications [43]. Numerous experimental and numerical studies have supported the predictive accuracy of the VGM for axisymmetric tension cases (i.e., notched and smooth round bars under uniaxial tension) [38,39]. However, a modification is required for the original VGM to account for the effects of temperature and cooling method on post-fire ductile fracture. The modified VGM is thus based not only on stress triaxiality and plastic strain, but also on the elevated temperatures and cooling methods. The following context begins with introducing the original version of the VGM for ductile fracture at room temperature, followed by the calibration of model parameters for ASTM A572 Gr. 50 after exposure to various elevated temperatures.

\subsection{Void Growth Model}

The void growth model was developed based on an infinite material matrix subjected to a remote stress field and with an isolated spherical void $[38,39]$. The material is idealized to be either perfect elastic-plastic or linear strain hardening. The analytical solution for the growth rate of the void radius is given as:

$$
\frac{\dot{\bar{R}}}{R_{0}}=\alpha \exp \left(\beta \frac{\sigma_{m}}{\bar{\sigma}}\right) \dot{\varepsilon}_{e q}
$$

where $\dot{\bar{R}}=\left(\dot{\bar{R}}_{1}+\dot{\bar{R}}_{2}+\dot{\bar{R}}_{3}\right) / 3$ is the average change rate of the radius in all three directions, $\bar{\sigma}$ is the flow stress, and $\dot{\varepsilon}_{e q}$ is the remote equivalent plastic strain rate imposed on the matrix. In the original void growth model, $\alpha$ and $\beta$ were determined to be 0.283 and 1.5, respectively. By integrating Equation (1), the change rater of the void radius is expressed as a function of stress triaxiality $\left(\eta=\sigma_{m} / \bar{\sigma}\right)$ and the remote plastic strain field. According to Rice and Tracey [42], the instant that the void radius exceeding the critical value over a characteristic length $1^{*}$ is considered to be the initiation of ductile fracture. The criterion is explicitly expressed as:

$$
V G I=\int_{0}^{\varepsilon_{e q}} \exp (\beta \eta) d \varepsilon_{e q} \geq V G I_{c r} \quad R>l^{*}
$$

where $V G I$ is used to quantify the void size, and $V G I_{c r}$ is the critical magnitude of void growth index at failure of the material matrix. Hancock and Brown (1983) [49] proposed that the parameter $\beta$ was within 1.1 and 2.3 for British Steels 50D and 50D N.N, Kiran and Khandelwal [45] suggested an approximated $\beta$ value of 1.15 for ASTM A992 steels. In this paper, the parameter $\beta$ is considered as a material parameter to be calibrated, rather than a constant. The characteristic length $l^{*}$ is considered as a length scale at fracture initiation, which implies that the condition in Equation (2) must be satisfied over a certain length.

\subsection{Characteristic Length}

The VGM criterion must be satisfied over a material volume with minimum size represented by the characteristic length $\left(l^{*}\right)$. This length parameter is measured using either inversed finite element analysis or experimental studies. Even though the FE approach can be numerically effective and can yield accurate results with respect to load-displacement response compared to experiments, the calibrated characteristic length is irrelevant to its physical representation. The more preferred method to determine the characteristic length is based on physical interpretations and microstructural features. A widely accepted measurement of the characteristic length is the size of microvoid clusters [21,26], which is 
also adopted in the present study. The underlying physics behind ductile fracture initiation is the linkup of multiple voids, either by internal necking or shear strain localization, i.e., void coalescence. These linked voids, due to enlargement during the phase of void growth and localization of ligaments between neighboring voids during the phase of void coalescence, appear as clusters of inclusion colonies [38,39,45,50]. Estimation of the characteristic length involves averaging the measured micro-cluster sizes over a number of typical microvoid clusters at the fractured surfaces. Based on this approach, the measured characteristic length scales are well documented for mild steels Q235, Q345 [51], ASTM A36 [52], as well as high strength steels Q460 [51], ASTM A992 [45], and ASTM A572 Gr. 50 [38]. Previous studies indicated that the measure length scales for mild and highstrength structural steels shows a large deviation for a given steel grade [38,50], typically varying from 0.1 to $0.3 \mathrm{~mm}$.

Determination of the length scale for A572 steels after being cooled down from elevated temperatures is based on the results of SEM analysis. Firstly, the reported length scales for ASTM A572 steels at room temperature from various studies $[37,38]$ can be used to infer the micro-cluster sizes in post-fire A572 specimens. According to the comparative SEM fractography studies on A572 steels, including RT specimens and specimens cooled after exposure to $1000{ }^{\circ} \mathrm{C}$ (Figure 7), the average micro-cluster size on various fractured surfaces for the latter specimens is $0.5 \sim 0.7$ times the former, due to microstructure changes that the steel specimens experienced during heating and cooling. Secondly, direct measurements of micro-cluster sizes for SPR-1000-AC and SPR-1000-WC specimens resulted in length scales ranging from $0.08 \mathrm{~mm}$ to $0.15 \mathrm{~mm}$. Therefore, the length scale for A572 Gr. 50 steels cooled from elevated temperatures is assumed to be constant at $0.1 \mathrm{~mm}$, irrespective of temperature and cooling method. Moreover, this estimation does not affect the accuracy of the VGM because the un-notched and notched specimens employed in this study have mild or low stress/ strain gradients at the critical cross-section, which allows the prediction to be relatively insensitive to length scale [38,49]. However, more accurate length scale measurements and estimates for different post-fire steel specimens are favorable for application of the VGM.

\subsection{Calibration of the Parameters $\beta$ and $V G I_{c r}$}

Besides the estimated characteristic length $\left(l^{*}\right)$, the VGM criterion requires the determination of two other parameters $\left(\beta, V G I_{c r}\right)$. The calibration of the two model parameters requires information about the initiation of ductile fracture in each specimen. The instant of fracture initiation is typically measured using the experimental load-displacement response.

Fracture initiation is marked by the point at which the load-carrying capacity suddenly drops (marked point in Figure 5), which is widely accepted for smooth-notched and unnotched tensile round specimens, because crack initiation and propagation are confirmed to occur almost simultaneously over the entire critical cross-section [38]. As the steels cooled from elevated temperatures exhibited similar fracture mechanism and load-displacement responses as the room temperature steels, they are believed to show fracture initiation at the point of load sudden drop.

In this study, an iterative procedure is adopted for calibrating the VGM parameters $\left(\beta, V G I_{c r}\right)$. First, a value for parameter $\beta$ is assumed. For a given notch, the void growth index VGI to fracture initiation at every location is determined using Equation (2). $V G I_{c r}$ is estimated as the value of $V G I$ being exceeded over the characteristic length $l^{*}$ across the critical cross-section and under a given $\beta$. Repeating the process for various magnitudes of $\beta$ gives the best estimate of $\beta$, at which a minimal coefficient of variation in $V G I_{c r}$ is obtained. $V G I_{c r}$ is calibrated as the average value across all notches at the calibrated $\beta$. The calibration procedure results in the VGM parameters listed in Table 2 for A572 Gr. 50 steel specimens cooled after exposure to elevated temperatures. The estimated $\beta$ varies from 1.0 to 2.2, and the estimated $V G I_{c r}$ ranges from 2.03 to 4.17. The calibrated VGM parameters for A572 Gr. 50 steels at room temperature are comparable to the reported magnitudes in the literature [38]. Note that the specimens, though made of the same steel grade, have 
different VGM parameters, suggesting that the temperature and cooling method have significant effects on ductile fracture initiation. A detailed discussion about this point is provided in the next section.

Table 2. VGM parameters for A572 Gr. 50 steels subjected to various temperatures and cooled by different methods.

\begin{tabular}{ccccc}
\hline Temperature $\left({ }^{\circ} \mathbf{C}\right)$ & Cooling Method & $\boldsymbol{\beta}$ & $\boldsymbol{V G I}_{\boldsymbol{c r}}$ & COV \\
\hline RT & - & 1.7 & 3.84 & 0.118 \\
500 & AC & 1.4 & 2.81 & 0.136 \\
& WC & 1.7 & 3.35 & 0.147 \\
600 & AC & 1.9 & 4.17 & 0.095 \\
& WC & 1.9 & 4.03 & 0.138 \\
700 & AC & 1.7 & 3.50 & 0.171 \\
& WC & 1.5 & 2.92 & 0.126 \\
800 & AC & 1.0 & 1.64 & 0.151 \\
& WC & 1.6 & 2.03 & 0.200 \\
900 & AC & 1.8 & 4.17 & 0.094 \\
& WC & 2.2 & 3.83 & 0.127 \\
1000 & AC & 1.4 & 2.60 & 0.104 \\
& WC & 1.5 & 2.19 & 0.126 \\
\hline
\end{tabular}

\subsection{Simulation of Ductile Fracture Initiation Using VGM}

Ductile fracture initiation in each notch can be predicted using FE simulations and the calibrated VGM. The predictive accuracy of the model is evaluated through comparison between the predicted ductile fracture initiation and the experimental results. As the point where the load-carrying capacity suddenly drops is commonly used to represent the instance of ductile fracture initiation in the smooth-notched round specimens, ductility (displacement at load suddenly dropping to the initial gauge length) is adopted in this paper as another measure of fracture initiation. Figure 8 compares the predicted and experimental ductility of each specimen. For most of the specimens, the ductility data points are within the $25 \%$ margin lines, indicating good agreement between tests and the VGM prediction (Figure 8). Note that the ductility of the five specimens in a given group (subjected to the same temperature and cooled using the same method) is represented using the same symbol. Therefore, the comparison provided in Figure 8 reflects the overall VGM performance, independent of stress triaxiality.

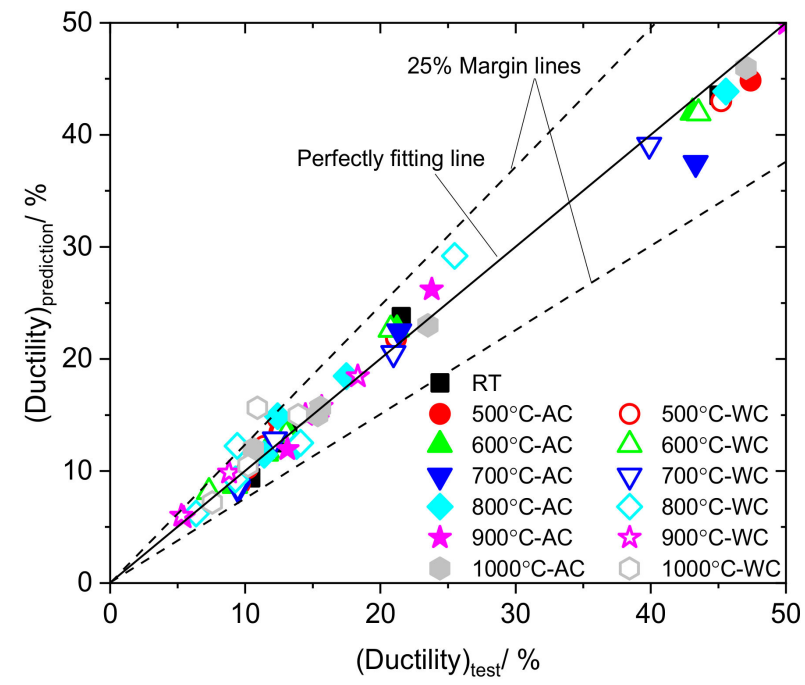

Figure 8. Comparisons of specimen ductility between VGM prediction and tests. 
In addition to the displacement at fracture initiation (ductility), the location of fracture initiation can also be predicted using the VGM and FE analyses. First, the local region with a void growth index that satisfies the criterion in Equation (2) at the earliest time is determined as the site of fracture initiation. For the sake of simplicity, the specimens for $\mathrm{RT}, 800^{\circ} \mathrm{C}-\mathrm{AC}$, and $800^{\circ} \mathrm{C}-\mathrm{WC}$ are examined to compare the location of fracture initiation and the distribution of VGI over the critical cross-section of each notch. Figure 9 shows the contours of VGI at the instant of fracture initiation for the three groups of specimens. For each specimen at room temperature, the maximum VGI appears at the center of each notch, indicating that the cross-sectional center may be the site of fracture initiation. For the RT case, the distribution of the VGI varies for different specimens due to varying strain and stress gradients produced by notches. However, the center of the cross-section is not necessarily the location of fracture initiation for notched specimens cooled from elevated temperatures. For the notches $\mathrm{CN} 1-800{ }^{\circ} \mathrm{C}-\mathrm{AC}$, UN1-800 ${ }^{\circ} \mathrm{C}-\mathrm{AC}, \mathrm{CN} 1-800{ }^{\circ} \mathrm{C}-$ $\mathrm{WC}$, and UN1-800 ${ }^{\circ} \mathrm{C}-\mathrm{WC}$, the fracture likely initiates at the notch periphery. Deviation in the location of fracture initiation is attributed to changes in the stress field (stress triaxiality) over the cross-section as well as ductile fracture properties (e.g., sensitivity to stress triaxiality). This is because changes in steel microstructures due to heating and cooling are responsible for changes in plastic flow and fracture behavior, and thus the variation in fracture initiation.
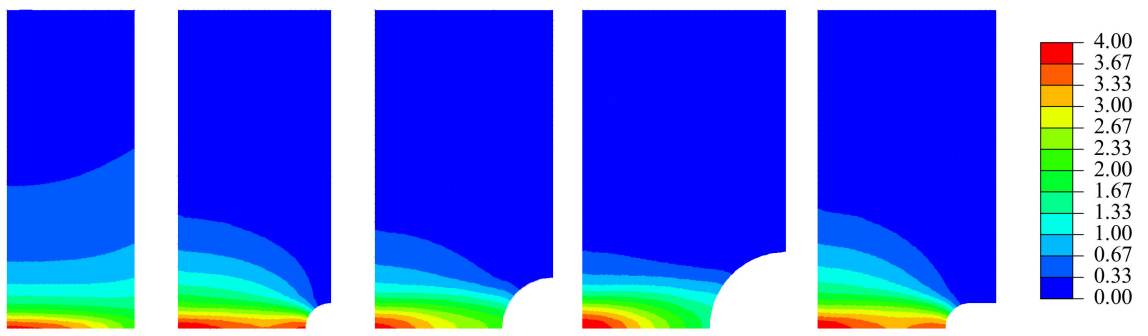

(a)
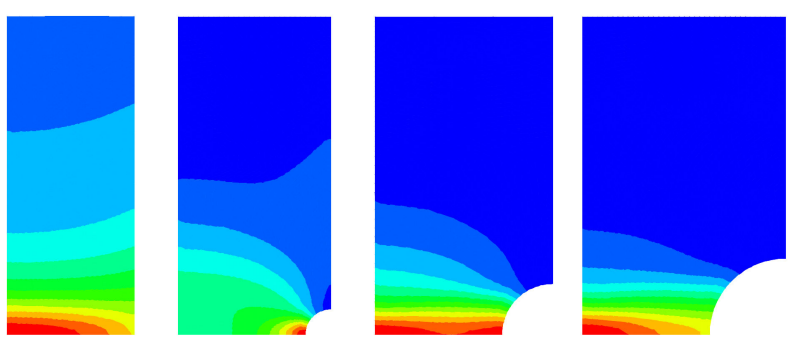

(b)
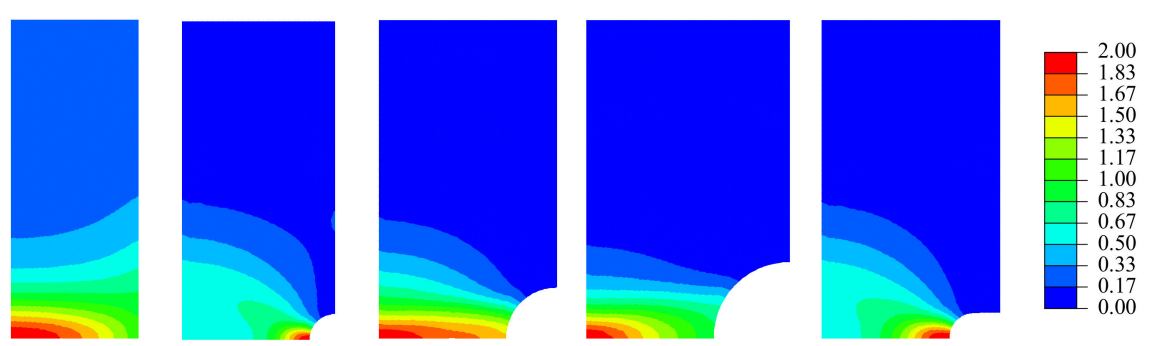

(c)

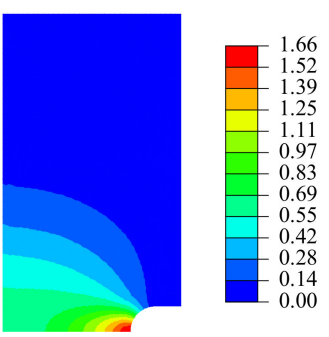

\author{
(1) \\ (1)
}

Figure 9. Contour of VGI index at fracture initiation in steel specimens, (a) RT, (b) $800{ }^{\circ} \mathrm{C}-\mathrm{AC}$, and (c) $800{ }^{\circ} \mathrm{C}-\mathrm{WC}$.

\title{
6. Post-Fire VGM Model Incorporating Temperature and Cooling Method
}

For steels subjected to high stress triaxialities, the accumulative void growth index and fracture initiation are strongly dependent on the evolution of equivalent plastic strain and 
stress triaxiality. As discussed previously, changes in the microstructure become another important parameter influencing the fracture behavior for steels after cooling down from elevated temperatures. Evidence for this can also be found in the literature [1]. Qualitative analyses of the effects of temperature and cooling method are provided for post-fire A572 steels [1]. This section is aimed at further developing a quantitative tool for evaluating the sensitivity of ductile fracture parameters to temperature and cooling method. The VGM model is again used as the basis of the quantitative method by accounting for the effects of temperature and cooling scenarios.

\subsection{Effects of Temperature and Cooling Method on Fracture Initiation in A572 Steels}

Experimental ductility data for the post-fire specimens are adopted to re-examine the effects of temperature and cooling method on the displacement to fracture in each specimen [1]. To eliminate the influence of specimen geometry, a comparison of ductility is performed among the specimens subjected to various temperatures and with the same notch. To this end, the ductility residual factor, introduced to quantify the post-fire ductility of structural steels, is defined in this study as the ratio of the ductility of a specimen cooled down from a specific elevated temperature (e.g., ductility for CN3-500-AC) to that of the corresponding RT specimen with the same notch (e.g., ductility for CN3-RT). The ductility residual factor for each specimen is provided in Figure 10. For most of the AC specimens, the ductility residual factor is larger than 1.0. The smallest magnitude is 0.93 for the specimen $\mathrm{CN} 1-800-\mathrm{AC}$, indicating that the heating and air-cooling process has, in general, a positive effect on specimen ductility. The increase in ductility is more apparent for specimens after heating to temperatures beyond $700{ }^{\circ} \mathrm{C}$ and cooling. The improvement in specimen ductility may be a result of the increase in ferrite grain size [12]. In contrast, specimens that are water-cooled after exposure to high temperatures exhibit significant reductions in ductility. The development of the brittle Martensite phase may be responsible for the decrease in ductility in the WC specimens [1]. The effect of the cooling method varies with temperature. For steel specimens subjected to $500{ }^{\circ} \mathrm{C}, 600{ }^{\circ} \mathrm{C}$, and $700{ }^{\circ} \mathrm{C}$, there is only a slight difference in the ductility of the specimens with the same notch after exposure to an identical elevated temperature using different cooling conditions (AC and WC). However, such differences become significant for the specimens subjected to very high temperatures $\left(T \geq 800^{\circ} \mathrm{C}\right)$.

Apart from the ductility, the local response at the location of fracture initiation, including stress and strain fields, is also informative for examining the effects of the temperature and cooling method. Due to the representative ductility residual factors for CN3-800-AC and CN3-800-WC (the former is greater than 1.0 while the latter is less than 1.0), the loading paths at the center of the critical cross-section in the two specimens along with that in CN3-RT are compared in Figure 11. Triaxiality is at the highest level in CN3-800-WC and at the lowest level in CN3-800-AC during the loading history, as stated previously. The reduction in ductility for CN3-800-WC, when compared to CN3-RT, may be partly attributed to the higher triaxiality at the location of fracture initiation. According to Equation (1), void growth can be accelerated with increasing triaxiality for a given material (with the given ductile fracture properties). As a result, the fracture in specimen CN3-800-WC initiates at the lowest plastic strain among the three cases. Comparing CN3-RT and CN3-800-AC shows that the former, though with larger stress triaxialities, causes fracture initiating at larger levels of plastic strain compared to the latter, which can be attributed to the fact that the sensitivity of fracture to triaxiality (measured by the ductile fracture parameter $\beta$ ) in $\mathrm{CN} 3-800-\mathrm{AC}$ is reduced due to the air-cooling process after exposure to $800^{\circ} \mathrm{C}$. It is worth noting that a relatively large strain to fracture (local response) is not necessarily associated with a large displacement to fracture (global response) because of variation in the plastic flow behavior between the two specimens. 

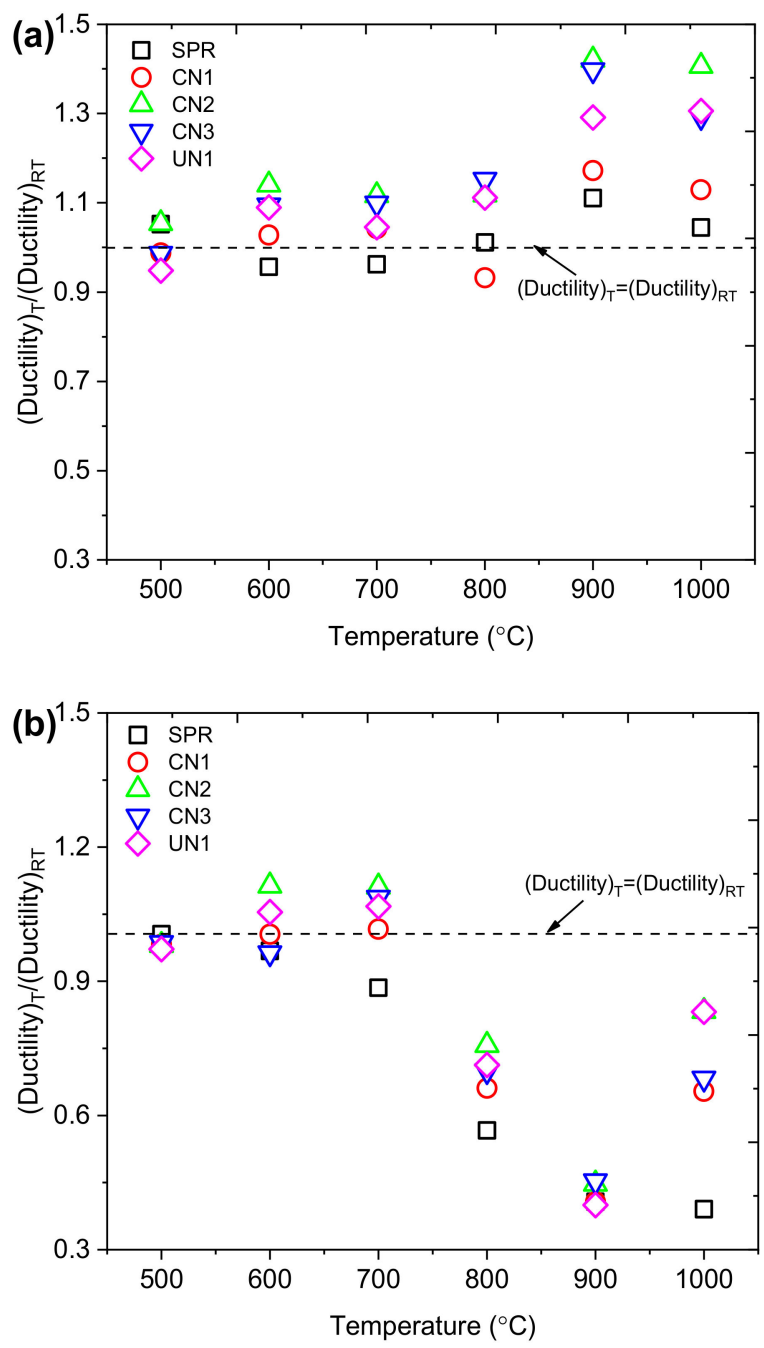

Figure 10. Ductility residual factors of the test specimens, (a) cooled in air, and (b) cooled in water.

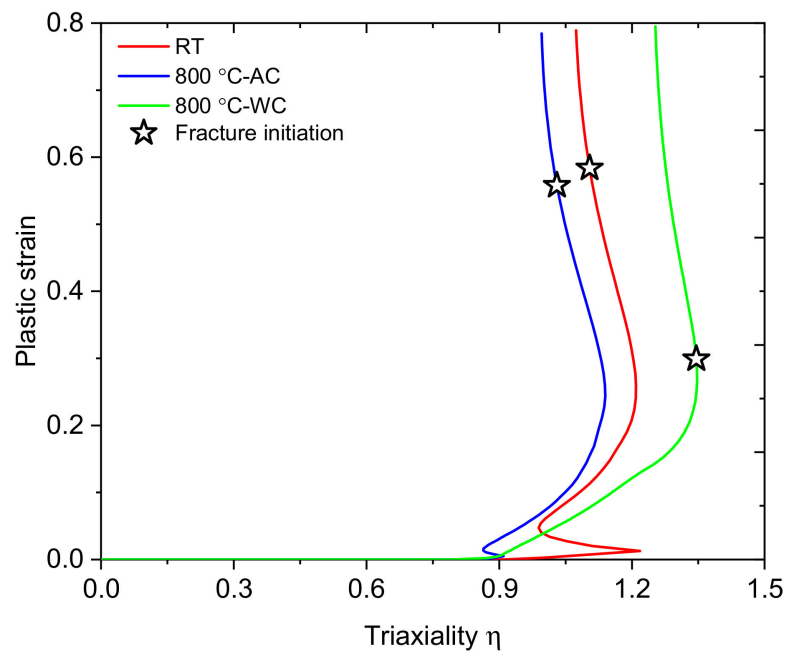

Figure 11. Effects of temperature and cooling method on the loading path of the CN3 specimens (star symbols denote the instance of fracture initiation).

\subsection{Dependence of Fracture Properties on Temperature and Cooling Method}

Temperature and cooling method have significant influences on the loading path (triaxiality history), as well as material ductile fracture properties. The preceding sections 
have provided a qualitative evaluation of these effects. To provide a quantitative tool for predicting ductile fracture initiation in post-fire steels, this section aims to examine the dependence of ductile fracture parameters on the temperature and cooling method. The calibrated VGM parameters listed in Table 2 allows for the establishment of the relationship between the fracture properties of RT steels and steels cooled from elevated temperatures. VGM parameters for the RT and post-fire cases can be correlated through the following expressions:

$$
\begin{aligned}
& \beta(T)=\beta_{R T} \times f(T) \\
& V G I_{c r}(T)=V G I_{c r, R T} \times g(T)
\end{aligned}
$$

where $f(T)$ and $g(T)$ are two independent functions of temperature, T, and cooling method; $\beta_{R T}$ and $V G I_{c r, R T}$ are the VGM parameters for steels at room temperature. As discussed previously, the effect of cooling method on specimen ductility is insignificant for cases with $\mathrm{T} \leq 700^{\circ} \mathrm{C}$. The negligible effect is also confirmed on fracture properties $\left(\beta, V G I_{c r}\right)$ through the data provided in Table 2. Another important result that has been discussed in the preceding sections is the varying effect of temperature on ductility. When temperature is less than $800{ }^{\circ} \mathrm{C}$, the difference in ductility between RT specimens and steels cooled after exposure to elevated temperatures will likely be relatively small for both AC and WC cases. In contrast, for steels subjected to elevated temperatures greater than $800{ }^{\circ} \mathrm{C}$, the heating and cooling process significantly influences the specimen ductility. Similar phenomena have also been described in the literature for both ASTM A572 Gr. 50 [1] and A36 steels [12]. Based on the qualitative findings, an iterative process is introduced, resulting in two piecewise-defined functions that determine the best fit for the calibrated VGM parameters (Figure 12). Both the piecewise functions are provided below.

$$
\begin{array}{r}
f(T)=\left\{\begin{array}{lr}
-35.83(\log T)^{2}+198.86 \log T-274.79 & 500 \leq T<800 \\
-147.99(\log T)^{2}+876.04 \log T-1295.4 & A C: 800 \leq T \leq 1000 \\
-164.06(\log T)^{2}+967.83 \log T-1426.1 & W C: 800 \leq T \leq 1000
\end{array}\right. \\
g(T)=\left\{\begin{array}{lr}
-46.62(\log T)^{2}+258.71 \log T-357.83 & 500 \leq T<800 \\
-166.64(\log T)^{2}+988.99 \log T-1466.3 & A C: 800 \leq T \leq 1000 \\
-191.26(\log T)^{2}+1129.5 \log T-1666.5 & W C: 800 \leq T \leq 1000
\end{array}\right.
\end{array}
$$

In fact, $f(T)$ and $g(T)$ are measures of the post-fire residual factors of fracture properties. Through the temperature-dependent functions $f(T)$ and $g(T)$, the fracture parameters for steels at room temperature may be used to infer the values of $\beta$ and $V G I_{c r}$ for the corresponding steels, after heating and cooling down from elevated temperatures, without the need to carry out coupon heating and cooling, as well as mechanical tests. Alternatively, data from a small number of tests on the room temperature specimens for a few triaxialities could be used to develop the VGM model for predicting fracture initiation in steels cooled from elevated temperatures. However, the proposed modified VGM has two key limitations. First, the test data used for calibration of the residual functions in Equations (4) and (5) only apply to specimens exposed to temperatures between $500{ }^{\circ} \mathrm{C}$ and $1000{ }^{\circ} \mathrm{C}$, with an interval of $100{ }^{\circ} \mathrm{C}$, resulting in the availability of only three data points corresponding to each temperature regime (i.e., $500{ }^{\circ} \mathrm{C} \sim 700^{\circ} \mathrm{C}$ and $800{ }^{\circ} \mathrm{C} \sim 1000{ }^{\circ} \mathrm{C}$ ). This may adversely influence the predictive accuracy of the post-fire VGM that is applicable for cases with various temperatures. Additional test data with smaller temperature intervals are preferred for a more reliable calibration of the functions $f(T)$ and $g(T)$. Second, the characteristic length $\left(l^{*}\right)$ in the modified VGM is assumed to be a parameter independent of the temperature and the cooling method. The influence of this simplified assumption on the predictive performance of the proposed model has not been evaluated. Further improvement to the post-fire VGM model with respect to the characteristic length $\left(l^{*}\right)$ is required, either through physical calibration or through more accurate identification. 

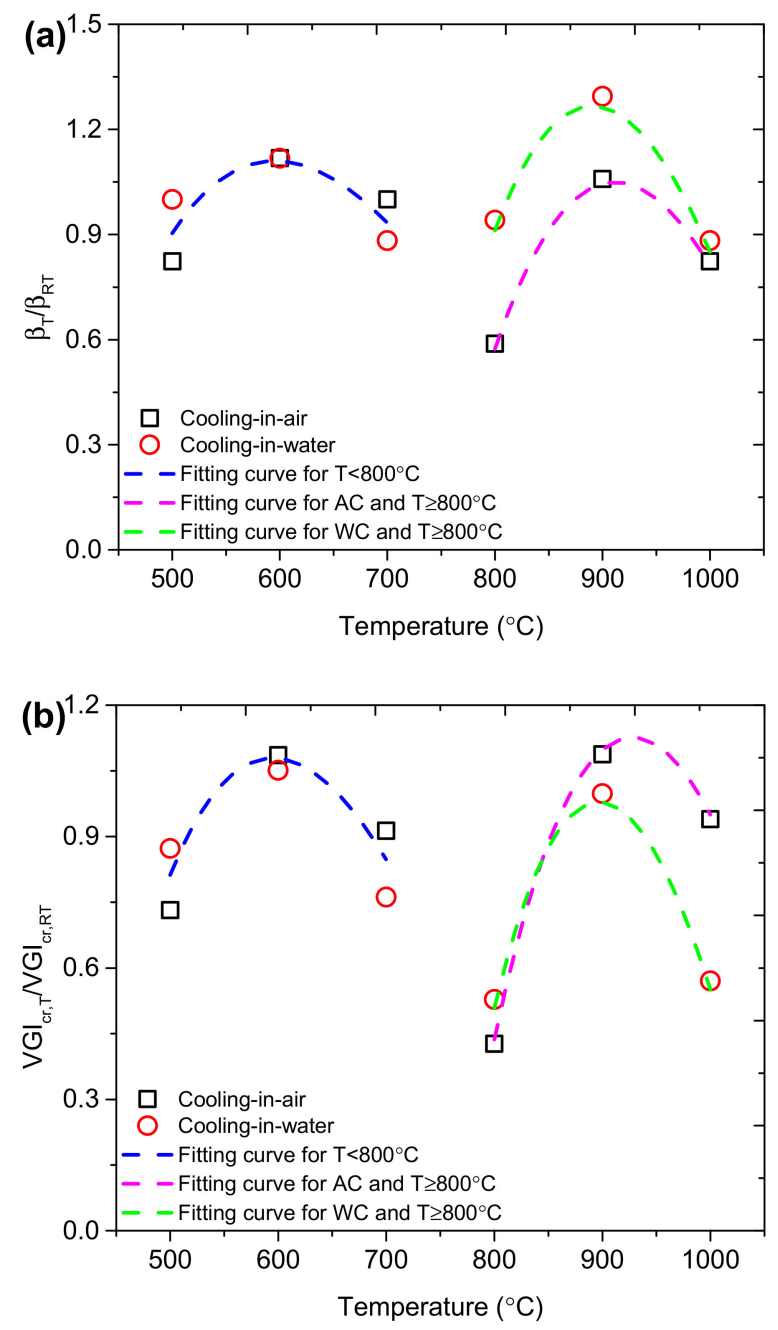

Figure 12. Dependence of VGM fracture parameters on temperature and cooling scenario, (a) VGM parameter $\beta$, and (b) critical fracture index $V G I_{c r}$.

\section{Summary and Conclusions}

Based on the results of the micromechanical analyses and the round bar tests presented in this paper, fracture initiation in the steel specimens after exposure to elevated temperatures still follows the ductile type. SEM fractographs show that the fractured surfaces consist of the micro-void coalescence (MVC) zone and the river-like surface, relevant to ductile fracture initiation and brittle fracture propagation, respectively. Although it leads to changes in the microstructures of the steel samples, the additional heating and cooling process is not likely to influence the micro-mechanisms of ductile fracture initiation and the ultimate failure mode. However, the heat treatment (e.g., temperature and cooling method), apart from the stress and strain parameters, becomes a crucial factor that influencing steel ductility.

Experimental data from ASTM A572 Gr. 50 steels that were subjected to varieties of elevated temperatures and cooled using two methods demonstrate that the VGM model has great potential in accurately predicting fracture initiation of the steels experienced heating and cooling process. The calibrated VGM parameters vary among the specimens with the same initial notch, while undergoing different heating and cooling histories. These variations reveal the changes in the sensitivity to stress triaxiality, the fracture toughness, and thus the fracture initiation in the steels after exposure to elevated temperatures. The effects of temperature and cooling method on the VGM parameters are relatively insignificant from $500{ }^{\circ} \mathrm{C}$ to $700{ }^{\circ} \mathrm{C}$ compared to those in the range from $800{ }^{\circ} \mathrm{C}$ to $1000{ }^{\circ} \mathrm{C}$. 
A modified VGM model is proposed for predicting ductile fracture in post-fire steels. Two additional residual factor functions are introduced to account for the effects of temperature and cooling method on VGM parameters. Using these two functions, calibration of the post-fire VGM requires only room temperature specimens covering a certain range of triaxialities, significantly lowering the experimental and computational costs of predicting ductile fracture in post-fire structural steels. However, the post-fire VGM is only calibrated using the test data from $500{ }^{\circ} \mathrm{C}$ to $1000{ }^{\circ} \mathrm{C}$. Further validation of the proposed post-fire VGM is required for steels other than ASTM A572 Gr. 50 and for steels exposed to temperatures other than those described in Sajid and Kiran [1]. Another remaining issue that needs addressing in the future is to accurately evaluate the characteristic length with respect to the steel after experienced to a given heating and cooling scenario. For many structural engineering situations (e.g., with sharp stress or strain gradients) that are sensitive to the length parameter, it is particularly important to characterize this dimension in a more accurate manner. Subsequent work following this study aims to develop practical, yet reliable means to the measuring the characteristic length.

Although this paper exploratively investigates the effect of the heating and cooling treatment (e.g., temperature and cooling method) on the fracture behavior of post-fire structural steels, more in-depth studies are needed in the further research to determine the effects of heating and cooling method on the underlying physics that controls the fracture mechanism. For instance, the effect of heating history (e.g., heating time and temperature history) on the micro-mechanisms of steel fracture initiation is still unresolved. Moreover, the cooled-in-water depends on the volume of water used and the flow rate of the water. These, relevant to the cooling rate, are probably the most critical parameters that influence the micro-mechanisms of post-fire fracture in structural steels. Therefore, it is quite important to provide a quantitative investigation on the effect of heat treatment on fracture mechanism in the future for a better understanding of the post-fire fracture behavior of structural steels.

Author Contributions: Conceptualization, Y.Z.; validation, S.H. and H.U.S.; formal analysis, Y.Z.; writing - original draft preparation, Y.Z.; writing — review and editing, S.H. and H.U.S. All authors have read and agreed to the published version of the manuscript.

Funding: This research was funded by National Natural Science Foundation of China, grant number 51908416, and Shanghai Pujiang Program, grant number 19PJ1409500. The author Shiping Huang acknowledges the financial support of "the Fundamental Research Funds for the Central Universities".

Institutional Review Board Statement: Not applicable.

Informed Consent Statement: Not applicable.

Acknowledgments: The authors want to thank Ravi Kiran of North Dakota State University for insightful comments and sharing of test data.

Conflicts of Interest: The authors declare no conflict of interest.

\section{References}

1. Sajid, H.U.; Kiran, R. Post-fire mechanical behavior of ASTM A572 steels subjected to high stress triaxialities. Eng. Struct. 2019, 191, 323-342. [CrossRef]

2. Evarts, B. Fire Loss in the United States during 2017; National Fire Protection Association (NFPA): Quincy, MA, USA, 2018.

3. American Society of Civil Engineers (ASCE). Structural Fire Protection; ASCE Committee on Fire Protection: Reston, VA, USA, 1992.

4. American Institute of Steel Construction (AISC). AISC 360-16-Specification for Structural Steel Buildings; AISC: Chicago, IL, USA, 2016.

5. Kodur, V.; Dwaikat, M.; Fike, R. High-Temperature Properties of Steel for Fire Resistance Modeling of Structures. J. Mater. Civ. Eng. 2010, 22, 423-434. [CrossRef]

6. Garlock, M.; Paya-Zaforteza, I.; Kodur, V.; Gu, L. Fire hazard in bridges: Review, assessment and repair strategies. Eng. Struct. 2012, 35, 89-98. [CrossRef]

7. Zhang, G.; Zhu, M.-C.; Kodur, V.; Li, G.-Q. Behavior of welded connections after exposure to elevated temperature. J. Constr. Steel Res. 2017, 130, 88-95. [CrossRef] 
8. Lou, G.-B.; Zhu, M.-C.; Li, M.; Zhang, C.; Li, G.-Q. Experimental research on slip-resistant bolted connections after fire. J. Constr. Steel Res. 2015, 104, 1-8. [CrossRef]

9. Yu, L. Behavior of Bolted Connections during and after a Fire. Ph.D. Thesis, University of Texas at Austin, Austin, TX, USA, 2006.

10. Outinen, J.; Mäkeläinen, P. Mechanical properties of structural steel at elevated temperatures and after cooling down. Fire Mater. 2004, 28, 237-251. [CrossRef]

11. Lu, J.; Liu, H.; Chen, Z.; Liao, X. Experimental investigation into the post-fire mechanical properties of hot-rolled and cold-formed steels. J. Constr. Steel Res. 2016, 121, 291-310. [CrossRef]

12. Sajid, H.U.; Kiran, R. Influence of stress concentration and cooling methods on post-fire mechanical behavior of ASTM A36 steels. Constr. Build. Mater. 2018, 186, 920-945. [CrossRef]

13. Yan, X.; Xia, Y.; Blum, H.B.; Gernay, T. Post-fire mechanical properties of advanced high-strength cold-formed steel alloys. Thin-Walled Struct. 2021, 159, 107293. [CrossRef]

14. Zhang, C.; Jia, B.; Wang, J. Influence of artificial cooling methods on post-fire mechanical properties of Q355 structural steel. Constr. Build. Mater. 2020, 252, 119092. [CrossRef]

15. Sajid, H.U.; Naik, D.L.; Kiran, R. Microstructure-Mechanical Property Relationships for Post-Fire Structural Steels. J. Mater. Civ. Eng. 2020, 32, 04020133. [CrossRef]

16. Ding, F.; Zhang, C.; Yu, Y.; Lan, L.; Man, M. Hysteretic behavior of post fire structural steels under cyclic loading. J. Constr. Steel Res. 2019, 105847. [CrossRef]

17. Wang, W.; Liu, T.; Liu, J. Experimental study on post-fire mechanical properties of high strength Q460 steel. J. Constr. Steel Res. 2015, 114, 100-109. [CrossRef]

18. Li, G.-Q.; Lyu, H.; Zhang, C. Post-fire mechanical properties of high strength Q690 structural steel. J. Constr. Steel Res. 2017, 132, 108-116. [CrossRef]

19. Qiang, X.; Bijlaard, F.S.; Kolstein, H. Post-fire mechanical properties of high strength structural steels S460 and S690. Eng. Struct. 2012, 35, 1-10. [CrossRef]

20. Chiew, S.; Zhao, M.; Lee, C. Mechanical properties of heat-treated high strength steel under fire/post-fire conditions. J. Constr. Steel Res. 2014, 98, 12-19. [CrossRef]

21. Lee, J.; Engelhardt, M.D.; Taleff, E.M. Mechanical Properties of ASTM A 992 Steel After Fire. Eng. J. 2012, 49, 33-44. [CrossRef]

22. Aziz, E.M.; Kodur, V.K. Effect of temperature and cooling regime on mechanical properties of high-strength low-alloy steel. Fire Mater. 2016, 40, 926-939. [CrossRef]

23. Cai, W.-Y.; Jiang, J.; Wang, Y.-B.; Li, G.-Q. Analysis of fracture behavior of high-strength steels in tension after fire exposure. Eng. Struct. 2021, 231, 111750. [CrossRef]

24. Siwei, C.; Shaokun, J.; Houzuo, G.; Huixuan, C.; Yifeng, L.; Kang, L. Mechanical and ductile fracture performances of high strength structural steel Q690 after a fire: Experimental investigation. Procedia Eng. 2017, 210, 496-503. [CrossRef]

25. Wang, F.; Lui, E.M. Experimental study of the post-fire mechanical properties of Q690 high strength steel. J. Constr. Steel Res. 2020, 167, 105966. [CrossRef]

26. Zhang, C.; Wang, R.; Song, G. Post-fire mechanical properties of Q460 and Q690 high strength steels after fire-fighting foam cooling. Thin-Walled Struct. 2020, 156, 106983. [CrossRef]

27. Kang, L.; Suzuki, M.; Ge, H.; Wu, B. Experiment of ductile fracture performances of HSSS Q690 after a fire. J. Constr. Steel Res. 2018, 146, 109-121. [CrossRef]

28. Azhari, F.; Heidarpour, A.; Zhao, X.-L.; Hutchinson, C.R. Mechanical properties of ultra-high strength (Grade 1200) steel tubes under cooling phase of a fire: An experimental investigation. Constr. Build. Mater. 2015, 93, 841-850. [CrossRef]

29. Zhang, C.; Wang, R.; Zhu, L. Mechanical properties of Q345 structural steel after artificial cooling from elevated temperatures. J. Constr. Steel Res. 2021, 176, 106432. [CrossRef]

30. Lu, J.; Liu, H.; Chen, Z.; Bisby, L. Experimental investigation of the residual mechanical properties of cast steels after exposure to elevated temperature. Constr. Build. Mater. 2017, 143, 259-271. [CrossRef]

31. Gunalan, S.; Mahendran, M. Experimental investigation of post-fire mechanical properties of cold-formed steels. Thin-Walled Struct. 2014, 84, 241-254. [CrossRef]

32. Ren, C.; Dai, L.; Huang, Y.; He, W. Experimental investigation of post-fire mechanical properties of Q235 cold-formed steel. Thin-Walled Struct. 2020, 150, 106651. [CrossRef]

33. Tao, Z.; Wang, X.-Q.; Hassan, K.; Song, T.-Y.; Xie, L.-A. Behaviour of three types of stainless steel after exposure to elevated temperatures. J. Constr. Steel Res. 2018, 152, 296-311. [CrossRef]

34. Ban, H.; Bai, R.; Chung, K.-F.; Bai, Y. Post-fire material properties of stainless-clad bimetallic steel. Fire Saf. J. 2020, $112,102964$. [CrossRef]

35. Ha, N.S.; Le, V.T.; Goo, N.S.; Kim, J.Y. Thermal Strain Measurement of Austin Stainless Steel (SS304) during a Heating-cooling Process. Int. J. Aeronaut. Space Sci. 2017, 18, 206-214. [CrossRef]

36. Le, V.T.; Ha, N.S.; Goo, N.S.; Kim, J.Y. Insulation System Using High-Temperature Fibrous Insulation Materials. Heat Transf. Eng. 2019, 40, 1523-1538. [CrossRef]

37. Sajid, H.U.; Kiran, R. Influence of high stress triaxiality on mechanical strength of ASTM A36, ASTM A572 and ASTM A992 steels. Constr. Build. Mater. 2018, 176, 129-134. [CrossRef] 
38. Kanvinde, A.M.; Deierlein, G.G. The Void Growth Model and the Stress Modified Critical Strain Model to Predict Ductile Fracture in Structural Steels. J. Struct. Eng. 2006, 132, 1907-1918. [CrossRef]

39. Jia, L.-J.; Kuwamura, H. Ductile Fracture Simulation of Structural Steels under Monotonic Tension. J. Struct. Eng. 2014, 140, 04013115. [CrossRef]

40. Bai, Y.; Wierzbicki, T. A comparative study of three groups of ductile fracture loci in the 3D space. Eng. Fract. Mech. 2015, 135, 147-167. [CrossRef]

41. Wen, H.; Mahmoud, H. New Model for Ductile Fracture of Metal Alloys. I: Monotonic Loading. J. Eng. Mech. 2015, $142,04015088$. [CrossRef]

42. Rice, J.; Tracey, D. On the ductile enlargement of voids in triaxial stress fields. J. Mech. Phys. Solids 1969, 17, 201-217. [CrossRef]

43. Zhu, Y.; Kiran, R.; Xing, J.; Pan, Z.; Li, L. A modified micromechanics framework to predict shear involved ductile fracture in structural steels at intermediate and low-stress triaxialities. Eng. Fract. Mech. 2020, 225, 106860. [CrossRef]

44. Dassault-Systèmes. ABAQUS/Standard Analysis User's Manual; Dassault Systèmes Simulia: Providence, RI, USA, 2016.

45. Kiran, R.; Khandelwal, K. Experimental Studies and Models for Ductile Fracture in ASTM A992 Steels at High Triaxiality. J. Struct. Eng. 2013, 140, 04013044. [CrossRef]

46. Pineau, A.; Benzerga, A.; Pardoen, T. Failure of metals I: Brittle and ductile fracture. Acta Mater. 2016, 107, 424-483. [CrossRef]

47. Bidulský, R.; Bidulská, J.; Gobber, F.S.; Kvačkaj, T.; Petroušek, P.; Actis-Grande, M.; Weiss, K.-P.; Manfredi, D. Case Study of the Tensile Fracture Investigation of Additive Manufactured Austenitic Stainless Steels Treated at Cryogenic Conditions. Materials 2020, 13, 3328. [CrossRef] [PubMed]

48. McClintock, F. A Criterion for Ductile Fracture by the Growth of Holes. J. Appl. Mech. 1968, 35, 363-371. [CrossRef]

49. Hancock, J.; Brown, D. On the role of strain and stress state in ductile failure. J. Mech. Phys. Solids 1983, 31, 1-24. [CrossRef]

50. Zhu, Y.; Engelhardt, M.D.; Kiran, R. Combined effects of triaxiality, Lode parameter and shear stress on void growth and coalescence. Eng. Fract. Mech. 2018, 199, 410-437. [CrossRef]

51. Liao, F.; Wang, M.; Tu, L.; Wang, J.; Lu, L. Micromechanical fracture model parameter influencing factor study of structural steels and welding materials. Constr. Build. Mater. 2019, 215, 898-917. [CrossRef]

52. Myers, A.T.; Kanvinde, A.M.; Deierlein, G.G. Calibration of the SMCS Criterion for Ductile Fracture in Steels: Specimen Size Dependence and Parameter Assessment. J. Eng. Mech. 2010, 136, 1401-1410. [CrossRef] 